\title{
Analysis on the Current Adult Guardianship System from the Perspective of Codification of the Chinese Civil Code
}

\author{
Xiangyu Chen \\ School of Public Administration \\ University of Electronic Science and Technology of China \\ Chengdu, China
}

\begin{abstract}
In the face of the outstanding situation of the aging of the society, there is a serious disconnection between the theory and practice of the current domestic adult guardianship system, and the existence of the guardian is not completely covered. the system design is preconceived in the first place - taking the defect of the person under guardianship's behavior ability as the premise, taking guardians as the center, ignoring the wishes and maximization of the person under guardianship' interests, absence of custody supervision system and guardianship Property Liquidation System, the abuse of the guardian's rights, etc. At present, when the civil code of our country is compiled, involving the arrangement of the content system and logical structure of the civil code, the new research on adult guardianship system is of great value in theory and practice, the scope of application of the subject should be expanded moderately, the adult guardianship system should be decoupled from the behavioral capacity system, the simple and rude "onesize-fits-all" should be abandoned when the guardianship procedure is started, and the relevant legislation of the "Dutch Civil Code" should be consulted, to implement trust management and flexible protective guidance to adult guardianship, to establish and perfect guardianship supervision system, to scientifically and comprehensively examine the subject qualification of guardians and to limit their rights, the adoption of such a series of legislative provisions makes the current system of adult guardianship in the Civil Code of our country, which is now being codified, in line with the concept of international human rights protection.
\end{abstract}

Keywords-adult guardianship; autonomous guardianship; guardianship supervision; civil code

\section{INTRODUCTION}

Under the background of the new era, the problem of global population aging is becoming more and more prominent. Therefore, both countries of the two legal systems have carried out corresponding reforms to the adult guardianship system to meet the needs of judicial practice, and have achieved remarkable results in the world. "A contemporary system of adult guardianship, centered on the independence and selfdetermination of adults with or partially incapacitated civil capacity and the disabled, has been established." At present, there are not a few researches on adult guardianship system in Chinese academic circles, which have made an indelible contribution to the publication of General principles of Civil Law and the compilation of Civil Code. For example, Yang Lixin points out that the current guardianship system confuses the relationship between guardianship and parental power, and the orientation in civil law is not accurate and clear, resulting in the confusion of its structure system, and the limitation of the scope of ward shows that the legislative blank is too large, far from being able to meet the needs of judicial practice, it is necessary to "establish a broad guardianship system of parental authority, guardianship and care of the trinity, expand the scope of the ward and focus on the protection of the lawful rights and interests of mental patients and plant mans [1]; Du Qishun expounds the recent promulgation of the General principles of Civil Law in China, extending the provisions of the old law on the regulation of guardianship in the chapter on natural persons of civil subjects, and according to the defects existing in the current adult guardianship system, it is pointed out that the compilation of the Civil Code requires the introduction of a legislative system based on the principle of "unified guardianship". The qualification conditions of the guardian subject should be stipulated scientifically and strictly, and clearly dividing the classification of adult guardianship system. "Perfecting the adult guardianship system of our country by increasing the system of interdiction and establishing the supervision mechanism of guardianship" [2]. Meng Qiang compares and analyzes the history of law making in different countries, pointing out the direction of reform and development of the contemporary global adult guardianship system: from the former unilateral emphasis on the security of property transactions of the ward and the neglect of its physical and mental health to the popular idea of human rights protection, from "other protection" adult guardianship to pay attention to the self-consciousness of the guardian. To sum up, each has its own strengths, constantly promoting the perfection of China's adult guardianship legislation system.

China's adult guardianship system has taken shape in the era of general principles of civil law, but with the continuous development of our society, the adjustment and upgrading of economic structure and the aging of the elderly population are prominent. So that the legal provisions in the General principles of Civil Law can no longer adapt to the development and innovation of academic theory, which also can not adapt to 
the needs of the judicial practice of the society. In 2012, the new article 26 of the Law on the Protection of the Rights and interests of the elderly of the People's Republic of China stipulated the elderly guardianship system in our country, which was the first reform of the adult guardianship system in China, which shortens the gap between China and the developed countries represented by British and American countries in the reform process of adult guardianship system. Now, when our civil code is being compiled, in order to respond to the social concern and meet the needs of practice, the General principles of Civil Law have explicitly stipulated the system of adult will guardianship, which is in fact a great progress of legislation. However, there is still much room for legislative progress due to the excessive principle of laws and the absence of guardianship supervision system.

\section{THE DEVELOPMENT AND DEFICIENCY OF ADULT GUARDIANSHIP SYSTEM IN CHINA}

The development of the guardianship system has long been a long time, there is still a great gap in legislation for adult guardianship system. Until the end of 2012, the standing Committee of the National people's Congress amended the Law on the Protection of the Rights and interests of the elderly, and the agreed guardianship of the elderly was reflected in Article 26. However, since the scope of the applicable population is limited to the elderly, far from covering the people who need to be guarded or cared for because they have lost or partially lost their capacity for civil conduct, Therefore, it does not mean that China's adult guardianship system is perfect and consistent with the concept of international human rights protection.

Nevertheless, the Law on the Protection of the Rights and interests of the elderly has still gained some legislative experience. The General principles of Civil Law, on the basis of the General principles of Civil Law and the Law on the Protection of the Rights and interests of the elderly, extend the coverage of adult guardianship from only the mentally ill mentally ill persons and the elderly are extended to persons with no capacity for civil action or to limit their capacity for civil conduct. Article 21-22 General legislation provides only for the circumstances under which a person with no capacity for civil action and a person with limited capacity for civil conduct are considered to have no capacity for civil conduct, without any specific explanation of the reasons. So, which makes the provisions have great tension and avoid onesidedness in scope, the loophole in the legislation has been narrowed. In Article 33 of the General principles of Civil Law, it is added that the arbitrary guardianship of the ward and the former statutory guardianship, together with the designated guardianship, constitute the type system of adult guardianship system in China. Guided by the principle of autonomy of private law in the civil law, the academic circles generally think that arbitrary guardianship is the key, the formal establishment of the system in the general principles of civil law indicates that adults can sign the guardianship agreement through the effective exercise of self-determination in their conscious and discerning ability, so as to protect their legitimate rights and interests, it is a great progress of the legislation.
With the transformation of society, the development of economy and the adjustment of family members' structure, China's adult guardianship system is facing endless challenges. To some extent, these challenges have forced China to improve the legislative level of civil code codification and the perfection of judicial practice.

First of all, the civil legislation of our country does not distinguish the adult guardianship system according to the different capacity of the ward, only from the perspective of typology, our legislation adopts a unified mode. On the other side of the strait, the Taiwan area of China adopts the dichotomy of guardianship and subsidiarity: the guardianship system is applicable to "unable to make an expression of will or unable to recognize and judge the effect of its expression, although it has received an expression of will."[3]; the auxiliary system is applicable to those whose ability to express the effect of will is obviously insufficient. It can be seen from this that compared with Taiwan in China, the unitary legislative model of the mainland does not distinguish between the individual needs and the actual situation of the person under guardianship, although to a certain extent it avoids duplication and confusion in the concept of division, however, "one size fits all", the "integration" provisions not only did not take care of the inner needs and autonomy of the ward, and even excessive guardianship care to some extent has become a burden, but also added obligations to the guardian, it is unfavorable for judicial practice to be efficient and simple, which runs counter to the idea of "convenience for the people and the benefit of the people".

Secondly, although the General principles of Civil Law have relaxed the main body restrictions which can be included in the scope of guardianship, drawing on the previous legislative experience, the common subjects, such as mental patients, vegetative persons and persons with mental retardation, are included in the legislative protection objects ,however, there are still some people who are unable to bear the consequences of their own civil and commercial activities and bring heavy burdens to their families because of illness or certain hobby factors, such as drunkenness, hallucinations caused by drug use, gambling, etc, which not only damages the legitimate rights and interests of the relative party who deals with it, but also does not help to maintain the stability of social order. In addition, due to the rapid development of urbanization in China, the rural labor force has been largely lost, since the strict implementation of the family planning policy in the 1980s, the number of empty nesters or the elderly living alone has become more and more. Most of these old people are not vigilant, lack of security awareness, so that they become the bait of all kinds of scams in society, have been cheated of life savings. In the "Thirteenth Five-Year Plan for the Development of the cause of ageing and the Construction of the Old-age system" , China pointed out that by the 2020 s or so, the number of empty nesters in society will increase to about 118 million. This shows that it is necessary to bring empty nesters or solitary elders into the scope of guardianship. Another cruel situation is that these old people often face an embarrassing situation in which their children work in other places, their parents have passed away and their spouses are too old to be responsible for guardianship, 
therefore, according to the traditional order to determine the guardian of this practice is not strong. Although the "General principles of Civil Law" stipulates adult arbitrary guardianship, but also for the civil affairs department to set the bottom obligations, but in practice, there is often a natural person or organization with guardianship qualifications of the phenomenon of prevarication.

Furthermore, in the establishment of guardianship supervision system, the General principles of Civil Code have not made any breakthrough compared with the General principles of Civil Law. Article 34, paragraph 3, of the General principles of Civil Code follows the same line of Article 18, paragraph 3, of the General principles of Civil Law. It simply stipulates that when the guardian infringes upon the legal rights and interests of the ward, he shall bear the responsibility, which in a sense is also a kind of legislative provision of guardianship supervision, but the scope of application of the subject of guardianship supervision, the way of guardianship supervision and the content of guardianship supervision are not elaborated in detail, leaving a large legislative blank. The legislature explained that the revocation of guardianship in Article 36 of the General provisions of the Civil Code could have the effect of guardianship supervision, however, the individuals or organizations entitled to apply to the court for revocation of guardianship in this article can only be included in "other persons with guardianship qualifications according to law", which makes judicial practice quite difficult, because of its less feasibility, the provision is often mere formality. The absence of a special guardianship authority also makes the law less feasible.

Finally, due to the imperfection of guardianship supervision mechanism in our country, there are legal loopholes in legislation, which are often accompanied by the abuse of guardianship power, which makes the rights of guardians not to be cured. Especially for some special groups, such as the mentally ill person, the elderly who have lost energy and intelligence, there is still a large legislative loophole in the relevant appraisal standard mechanism in our country, as a result, their close relatives, driven by economic interests, apply to the relevant departments for the abovementioned special groups to be "under guardianship." The Mental Health Act, issued in 2012, directly equates a person with mental disorders diagnosed by a psychiatrist with a restricted civil perpetrator, although psychiatric diagnosis is inseparable from the criteria for assessing civil capacity, even though the former is the premise and the medical basis of the latter, the diagnosis result cannot be roughly equated with the legal evaluation standard. As a rule, referrals who are close relatives are often transformed into guardians, driven by financial interests, or out of the drag of long-term care, or deliberately retaliate against others, So that the legal provisions used to protect the vulnerable groups become a tool for depriving the legal rights and interests of the "ward" and seeking illegal interests. It is precisely because of the vague role of the government and the very low level of participation in the current system of guardianship of persons with mental disorders that a guardian who is not in a position to be supervised has abused his power to make it compulsory for others to be diagnosed with mental illness or to be required to receive hospital treatment. It has seriously violated the right to personal liberty and the right to life and health of the patient.

\section{AN OVERVIEW OF THE REFORM OF THE ADULT GUARDIANSHIP SYSTEM OUT OF THE COUNTRY}

Due to the problems caused by the aging of the population, the international community pays close attention to the problem, and the idea of human rights is deeply rooted in the hearts of the people, and the research on the legislative protection of the disabled has also made great progress in the academic circles. In recent decades, both countries of the two legal systems have carried out relevant reforms of the adult guardianship system according to their actual national conditions and have made remarkable achievements, ranging from western Quebec in Canada, the Netherlands to Japan in the East, Taiwan in China, and so on. The contemporary adult guardianship system has been established through the vigorous and vigorous reform of the law.

The French Civil Code, which was regarded as the beginning of the civil code of the modern nation-state, did not set up the general rules, but the "person" was created precisely because of the special care and protection of the physically and mentally handicapped and the need to maintain the effectiveness of social market transactions, it is also a typical example of the logical structure since the succession of the legal ladder in Rome. "The German Civil Code" set up the general rules because of the expectation of the theorization effect, because of the limitation of the general principle frame structure. At the end of the 20th century, Germany enacted two successive laws, the Law on Reform of Adult Guardianship and Auxiliary Act and the Law amending Care Law and other provisions to supplement it. The requirement of maximizing the will and benefit of the disabled should be respected, and the system of auxiliary, guardianship and interdiction should be replaced by "legal care". It is worth mentioning that the German Civil Code, as amended, does not impose any restriction on the scope of the caretaker, but provides that the court shall select the caretaker according to the circumstances of the case, act for his economic affairs and take care of his or her accommodation, It shows respect for the discretionary power of the person under care. In the same vein, Taiwan is also the region of China, considering that the spouse and parents of the wards who are supposed to be guardians are not old enough to shoulder the duties of guardianship, the prescribed guardian order was deleted in 2008. Although both are civil law systems, but different from Germany's doctrine of authority, Taiwan regards application doctrine as a way of initiating protection, even distant relatives other than the four relatives may apply to the relevant authorities for guardianship as long as they meet the requirements of "having lived together in the last year." , because, in real life, living together in the last year is highly likely to have an accurate understanding of the mental state and living conditions of the ward, [4] and in that case there is no direct relationship between the degree of understanding and the closeness of blood relations, The measures of expanding the range of applicants in Taiwan make the legislation of adult guardianship system more flexible to meet the needs of judicial practice. The logic and legislative techniques of the Netherlands Civil Code, which adopted the 
improved Pandecton system, are worthy of reference in the compilation of the Civil Code of China: in the "law of human law and family law", adult guardianship, trust management and protective guidance to the guardians, as well as the state of body and mind and the condition of life, have been taken into account and the logical confusion in the legislative system is avoided.

The reform of adult guardianship system in AngloAmerican law system is also relatively perfect: in terms of requirements of guardian qualification restriction, British law provides that natural persons and legal persons may manage property matters. However, in the case of matters relating to human dignity, it can only be managed by natural persons; in order to ensure the true validity of the contract of guardianship, According to the relevant legislation in Britain, guardianship contracts must be made in writing and must be registered with the court of protection to make them effective. The principle of autonomy of will is adopted in the effective time of the contract, and the time agreed by the parties shall prevail. The reform of the British adult guardianship system, based on the three basic principles of "presumption of capacity", "minimum limit" and "best interest", the adult guardianship law reform commission was established in 2004 with the aim of achieving the objectives of protection, the degree of legal intervention is minimized, and the activities of the agent's ward affairs should be carried out between the minimum intervention scope to give the ward the greatest degree of autonomy. In the United States, medical custody has been criticized as a means of depriving the elderly of their dignity and choices, with opponents arguing that the adult guardianship system unduly restricts individual freedoms and the right to dispose of property under the pretext of protection. In this regard, the United States has been reflecting on the social problems brought about by overprotection and seeking the best balance of interests in the balance between autonomy and other governance. "The uniform Adult Guardianship and Protection procedure" Act promulgated by the United States fully respects the will autonomy of the person under guardianship according to the principle of minimum restriction, and moderately intervenes in the intervention of the public power, which greatly protects the legal rights and interests of the ward, the central position of limited guardianship was gradually established through a series of measures.

A strip of Japan with our country is one of the countries with one of the most serious problems of aging population in the world, and its mixed legislative model adopts the strong points of the two major legal systems. The Japanese Civil Code, revised in 1999, reformed the adult guardianship system: inherited the existing codification structure, In the logical system, the guardianship regulations related to the behavior ability are divided into the general rules and the protection of the disabled or partially incapacitated adults in the relative category, and the contents are adjusted and innovated in a wide range. The new system of guardianship and assistive care adopts the ternary mode of guardianship, aiding and assisting, and stipulates that the third person shall supplement the judgment ability of the disabled person, which requires respect for the will of the person under guardianship and its residual identification ability, to realize the gradual transformation from "other rule" to "autonomy". And in the special law on arbitrary guardianship system implemented in 2000, there is a special system of registration and supervision, in which registration refers to the establishment of guardianship contract on the basis of notarization. Supervision refers to Japan's unique two-tier supervision system of arbitrary guardianship, that is, adopting a two-track system of supervision, which consists of public power and private power [5], which is supervised by both the supervisor and the family court respectively. The supervisor has the right to request the guardian to report the guardianship affairs at any time, which belongs to the direct supervision, while the supervision of the family court is achieved through supervision of the guardianship superintendent, which belongs to the indirect supervision. Unlike the positive provisions of British law that provide for guardianship, Japan has restrictions only on the negative qualifications of arbitrary guardians and may act as arbitrary guardians of adults as long as they are not prohibited by law, this enables the guardian to have the guardianship ability and at the same time to protect the legal rights of the ward.

\section{SUGGESTIONS ON THE IMPROVEMENT OF ADULT GUARDIANSHIP SYSTEM IN THE CIVIL CODE}

On the basis of existing legislation, the Civil Code, which is now being codified, may consider the following suggestions.

\section{A. Typology and Diversification of Guardianship System}

According to the General principles of Civil Law, it can be seen that our country adopts a unitary type from the angle of whether to distinguish the capacity of behavior: China do not adopt different measures such as guardianship, curatorship or auxiliary according to the degree of lack of ability of adults, the adult guardianship system is uniformly applicable to adults without civil capacity or limited capacity for civil conduct. However, in terms of the content of the system, the adult guardianship system in the General principles of Civil Law can be divided into legal guardianship and adult arbitrary guardianship, the latter shows the basic principle of autonomy of private law in the civil law, compared with the former, adults may plan in advance the matters of guardianship that may occur in the future on the basis of the relationship with relatives and friends and the amount of their property, in order to avoid the rigidities and conservatism brought about by institutional decisions. Article 33 of the General provisions of the Civil Code specifies that when an adult in the arbitrary guardianship agreement is incapacitated or partially incapacitated, the agreement enters into force and the guardian begins to perform his guardianship duties. This indicates that the preferred application of adult guardianship is clearly defined in the form prescribed by law. Because the General principles of Civil Law in our country do not classify the situation of limited capacity, the human resources are often wasted in practice, which only adds to the judicial burden.

The typology of behavior ability has the advantages of clear and easy to carry out, convenient and efficient, which overcomes the defects of the procedure of case review, such as cumbersome procedure, high cost, low operability, etc., However, there are considerable problems in the hard 
classification of the civil behavior ability of the guardians on the basis of age, the level of intellectual development and the state of mind, and the absolute classification result cannot be completely consistent with the actual situation. Such a provision lacks comprehensive consideration, whether by case review or rigid "one-size-fits-all" classification, which is more or less extreme and absolute, so that there is no way to be thorough and exhaustive. In the design of the system of classification of civil capacity of the ward, it should be guided by principle and seek flexible methods and legislative techniques. Because of the characteristics of relativity and stage in the level of individual ability, it is very important to classify the behavior ability of adults not only at the technical level of legislation, but also on the implementation of human rights protection. Therefore, our country can refer to the trust management and flexible protective guidance of the adult guardianship regulation in the Dutch Civil Code, and change the embarrassing situation of "over-guardianship" or laissezfaire of the physically and mentally handicapped people who lacked the capacity of civil conduct before. If an adult is unable to carry out a factual legal act because of mental illness, physical disability, mental or mental handicap, he shall have the right to apply for arbitrary care of the person, and at the same time, Our country should integrate the system of quasi interdiction, curatorship and assistance from the institutional level to break the "integration" and "one size fits all" situation of adult guardianship. It not only perfects the legislative system, but also protects it thoroughly, meets the needs of the ward, and conforms to the idea of international human rights protection.

In a word, we can reasonably classify the protection measures and deal with the specific different types by means of protection, assistance and auxiliary, so as to better reflect the core spirit of the autonomy of the meaning of civil law and better conform to the principle of proportionality.

\section{B. Supplementing and Perfecingt the Supervision System of Adult Guardianship}

It is precisely because the provisions of Article 36 of the General provisions of the Civil Law on revocation of guardian qualifications indicate that the subject who can apply for revocation is "other persons with guardianship qualifications according to law", which makes the double identity of guardian and supervisor coincide, this in itself is a loophole in the law. In order to improve the guardianship supervision system, we must strictly examine the guardianship qualification on the basis of respecting the will of the ward itself, it is suggested that the civil affairs department be brought forward to the neighborhood committee and the village committee in the fourth paragraph of Article 28 of the Civil Law. This allows for timely and effective repair of the failure of the guardianship system by specialized agencies established by the Government when the status of guardians is being reviewed or when there is no adequate guardian in place, the specialized agencies, in accordance with their public power, add a security lock to the guardianship supervision system. In addition, guardians and guardianship supervisors should be separated from each other, and the responsibilities and obligations of guardianship supervisors should be clearly defined in legislation, such as regular reporting to third parties on the living conditions and property of the wards, when the guardian acts against the interests of the ward, he must stop and revoke his guardianship.

\section{Strengthening and Perfecting the Identification Standard of "Ward"}

The supervision of adult guardianship should not only focus on the process of guardianship, but also have much room for legislative progress in determining the standard of "ward" before guardianship. From the "Mental Health Law" in 2013, it can be seen that China's legislation has paid considerable attention to conform to the international trend, from medical guardianship to human rights guardianship, Article 30 clearly stipulates the "voluntary principle of hospitalization for mental disorders". This shows that our country, as a State party to the United Nations Convention on the Rights of Persons with Disabilities, is actively fulfilling its obligation to guarantee the rights of vulnerable groups of adults, it also shows that the adult guardianship system in China's reform process has gradually accepted and adopted the form of human rights guardianship to some extent, but it must also be recognized that due to the lack of supervision of the social soil, its implementation conditions need to be further followed up. Because the criteria for the identification of the concept of "mental disorder" are too vague to be able to manage the range of personal and property affairs, the standards of medical identification and legal recognition are often dealt with in a bundled manner, the different needs of individuals are ignored and the application of the same kind of guardianship measures without distinction usually results in the waste of resources and the damage to the human rights of the ward. Therefore, it is necessary to decouple the result of medical report from the standard of civil capacity determination and introduce the third party evaluation mechanism, so that the adult guardianship system can benefit the people.

\section{CONCLUSION}

At present, when our civil code is being compiled, with the development of economy and society, the aging of our country is becoming more and more serious, the reform of adult guardianship system is imminent. The author hopes to provide reference for the relevant legislation in this paper, in order to achieve the role of throwing bricks to lead jade.

\section{REFERENCES}

[1] Yang Lixin. The formulation of General Principles Of Civil Law and the perfection of guardianship system in China, Jurisconsult. 2016(01)

[2] Du Qishun. "On the Status and Legislative Perfection of Guardianship in the Marriage and Family System", Journal of Law.2017(08).

[3] Li Xia. "The Modern Turn of the Adult Guardianship System", Jurisprudence of China 2015 (2).

[4] Wang Rongzhen, Tang Qu. "Study on the Regulation of the System of Adults Arbitrary Guardianship in the Compilation of Civil Code", Forty-fifth edition of the rule of Law Forum.

[5] Man Hongjie. "Three Basic Problems in the Adult Guardianship System of General Principles of Civil Law (Draft)", Legal Forum.2017(1). 